\title{
Determination of the Distribution of the Substituent Group in Cellulose Acetate by Full Assignment of All Carbonyl Carbon Peaks of ${ }^{13} \mathrm{C}\left\{{ }^{1} \mathrm{H}\right\}$ NMR Spectra
}

\author{
Keisuke KowsaKa, Kunihiko OKAJIMA, and Kenji KamIDE* \\ Fundamental Research Laboratory of Fiber and Fiber-Forming Polymers, \\ Asahi Chemical Industry Co., Ltd., \\ 11-7 Hacchonawate, Takatsuki, Osaka 569, Japan
}

(Received March 30, 1988)

\begin{abstract}
An attempt was made to assign a number of peaks, observed in carbonyl region (168-171 ppm) of ${ }^{13} \mathrm{C}\left\{{ }^{1} \mathrm{H}\right\}$ NMR spectra of cellulose acetate (CA), to twelve magnetically different acetyl groups existing in 8 kinds of glucopyranose units constituting CA. CA samples with total degree of substitution $\langle\mathrm{F}\rangle$ ranging 0.43 to 2.46 were prepared by acid-hydrolysis of $\mathrm{CA}$ with $\langle\mathrm{F}\rangle=2.92$ dissolved in acetic acid. ${ }^{13} \mathrm{C}\left\{{ }^{1} \mathrm{H}\right\}$ NMR measurements were made on these ten CA samples in deuterated dimethylsulfoxide and 14 peaks in total were observed definetely over the whole range of $\langle F\rangle$ from $2.92-0.43$. From the spectra of CA samples with highest $\langle F\rangle(2.92)$ and lowest (0.43) carbonyl carbon peaks at $\mathrm{C}_{6}, \mathrm{C}_{3}$, and $\mathrm{C}_{2}$ positions in trisubstituted and monosubstituted glucopyranose units were successfully assigned. Deducing the effect of an acetyl group on the chemical shift of other acetyl groups, and vise versa, based on an empirical rule, 6 carbonyl carbon peaks in 3 kinds of disubstituted glucopyranose units were assigned. Eight average molar fractions $\left\langle\mathrm{f}_{l m n}\right\rangle\left(l=1\right.$ or 0 means that a hydroxyl group attached directly at $\mathrm{C}_{2}$ position is or is not substituted and $m=1$ or 0 means that $\mathrm{C}_{3}$ position is or is not substituted, and $n$ corresponds to $\mathrm{C}_{6}$ position) [i.e., $\left\langle\mathrm{f}_{000}\right\rangle,\left\langle\left\langle\mathrm{f}_{100}\right\rangle, \cdots,\left\langle\mathrm{f}_{111}\right\rangle\right]$ were evaluated from integrated intensity ratios. The probability of substitution at $C_{k}$ position $\left\langle\mathrm{f}_{k}\right\rangle(k=2,3$, and 6$)$ and $\langle\mathrm{F}\rangle$, both evaluated from the above $\left\langle\mathrm{f}_{l m n}\right\rangle$ values, fairly agree with those estimated by the conventional NMR method, indicating the validity of the assignment in this paper.
\end{abstract}

KEY WORDS Cellulose Acetate / ${ }^{13} \mathrm{C}$ NMR / Carbonyl Carbon / Degree of Substitution / Distribution of Substituent Groups /

Cellulose is a linear chain molecule with the chemical structure illustrated in Figure 1. Recently studies were actively carried out, in particular by Kamide et al., ${ }^{-5}$ on the distri-

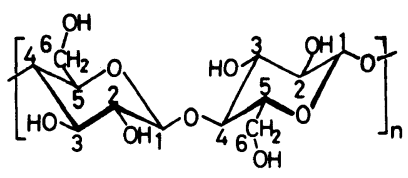

Figure 1. Chemical structure of cellulose: numbers (1-6) denote carbon positions.

* To whom all correspondence should be addressed. bution of the existing probability of substituent groups at three different hydroxyl groups $\left(C_{2}, C_{3}\right.$, and $C_{6}$ positions) in glucopyranose units constituting cellulose derivative molecules and its correlation with the physical and physiological properties. In these studies, .only the degrees of substitution at $\mathrm{C}_{2}, \mathrm{C}_{3}$, and $\mathrm{C}_{6}$ positions $\left\langle\mathrm{f}_{k}\right\rangle(k=2,3$, and 6$)$ were evaluated by NMR method. Note that $\left\langle\mathrm{f}_{k}\right\rangle$ values are averaged over all molecules contained in the sample, as well as all glucopy- 
ranose units constituting an individual polymeric chain, in other words, $\left\langle\mathrm{f}_{k}\right\rangle$ is a doublyaveraged quantity. ${ }^{1-5}$ Thus, the total degree of substitution was also expressed by $\langle F\rangle$. In addition, Kamide et al. $^{6}$ showed by thin-layer chromatography (TLC) that CA sample consists of molecules with different average total degrees of substitution $\langle\mathrm{F}\rangle$ [here, $F$ is the degree of substitution of a given glucopyranose unit and $\langle\mathrm{F}\rangle$ is obtained by averaging $F$ over all glucopyranose units constituting a single molecule] and evaluated the distribution of $\langle\mathrm{F}\rangle$, denoted as $g(\langle\mathrm{~F}\rangle)$ (see Figure

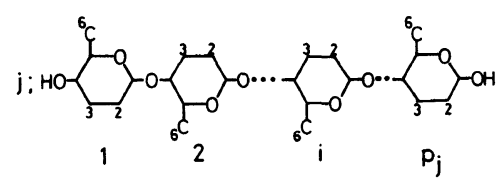

Figure 2. Schematic representation of the $j$ th cellulose molecule having the degree of polymerization, $p_{j}$.

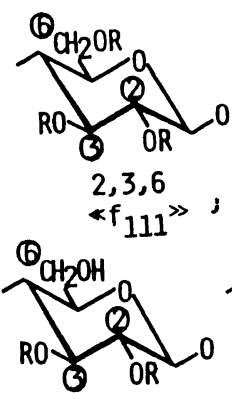

2,3-

\&f 110 》

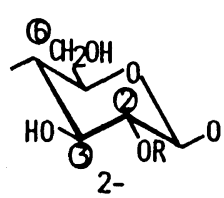

2-

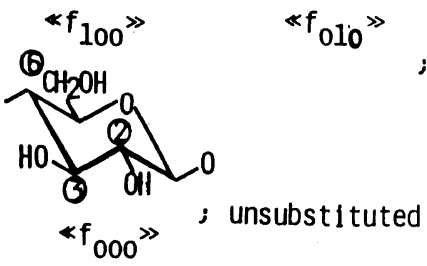

Figure 3. Substituted and unsubstituted glucopyranose units in CA molecules: $\left\langle\mathrm{f}_{l m n}\right\rangle$ represents molar fraction of the unit.
2). However, when we see the possible substituted glucopyranose units of cellulose derivative, there are 8 kinds of unsubstituted and partially or fully substituted glucopyranose units as shown in Figure 3: single trisubstituted, three disubstituted, three monosubstituted and one unsubstituted glucopyranose units. Molar fractions of these glucopyranose units $\left(\left\langle\mathrm{F}_{l m n}\right\rangle\right.$, defined later in detail $)$ are an effective measure of the distribution of the substitutent group within a glucopyranose unit, enabling us to also judge whether the reaction is homogeneous or not. Also, an accurate evaluation of these fractions is paramountly important in order to understand on a molecular basis the solubility of cellulose derivatives against various solvents and the physiological properties. Since the 1950's, the separation and quantitative determination of tri-, di-, mono-substituted and unsubstituted glucopyranose units have been exclusively performed by applying distillation and chromatographic techniques to chemically decomposed cellulose derivatives, particulaly sodium cellulose xanthate. ${ }^{7}$ However, the decomposition of cellulose derivative molecules into glucose units is extremely difficult without desubstituting reactions in spite of the numerous attempts to prevent such reactions. In fact, experimental results reported on $\left\langle\mathrm{F}_{l m n}\right\rangle$ of cellulose xanthate differ depending on researchers who carried out, unexceptionally, the conversion of the xanthate group into a more stable form through very complicated chemical reactions. ${ }^{3}$

$\mathrm{Wu}^{8}$ and Clark and Stephenson ${ }^{9}$ proposed methods for estimating molar fractions of 2,3,6-tri-, 2,6-di-, 3,6-di-, and 6-mono-substituted glucopyranose units of cellulose nitrates, whose $\mathrm{C}_{6}$ position was fully substituted (i.e., $\left\langle\mathrm{f}_{6}\right\rangle=1$ ) from their ${ }^{13} \mathrm{C}$ NMR spectra. However their methods cannot be applied to cellulose nitrate whose hydroxyl group at the $\mathrm{C}_{6}$ position is not fully substituted.

Kamide and Okajima ${ }^{10}$ were the first to give 
peak assignments to three roughly separated carbonyl carbon peaks of ${ }^{13} \mathrm{C}$ NMR spectra of $\mathrm{CA}$ in solution as the substitutent (acetyl) group at $\mathrm{C}_{3}, \mathrm{C}_{2}$, and $\mathrm{C}_{6}$ positions from higher magnetic field and showed that $\left\langle\mathrm{f}_{k}\right\rangle$ could be evaluated from the intensitity ratio of these three peaks. Later, Miyamoto et al. ${ }^{11}$ gave the reverse assignment on $\mathrm{C}_{2}$ and $\mathrm{C}_{3}$ positions using a principally similar method as Kamide and Okajima. Applying the low-power selective spin decoupling method to almost completely substituted $\mathrm{CA}(\langle\mathrm{F}\rangle=2.92)$, Kowsaka et al. ${ }^{12}$ assigned, from the lower magnetic field, the carbonyl carbon peaks to the acetyl groups at $\mathrm{C}_{6}, \mathrm{C}_{3}$, and $\mathrm{C}_{2}$ positions and simultaneously demonstrated that there are not only 3 but also many peaks in the carbonyl carbon region of ${ }^{13} \mathrm{C}$ NMR spectra of partially substituted CA $(\langle F\rangle=2.46$ and 0.68$)$, insisting that these peaks correspond to 12 carbonyl carbon peaks, originating from magnetically different all $(=12)-$ OR groups existing in 8 pyranose rings as shown in Figure 3. In order to evaluate 《f $\left.\mathrm{f}_{k}\right\rangle$ for not-fully substituted CA with good accuracy, the reliable assignment of the abovementioned 12 peaks is very prerequisite because rough classification of these peaks into three parts (carbonyl at $\mathrm{C}_{2}, \mathrm{C}_{3}$, and $\mathrm{C}_{6}$ ) made by Kamide and Okajima ${ }^{10}$ and Miyamoto et al. ${ }^{11}$ is too oversimplified, ignoring possible peak overlapping from different types of substituted glucopyranose units.

Both Miyamoto et al..$^{13}$ and Kamide and his collaborators $^{5}$ came to the same conclusion that CA samples with the same $\langle F\rangle$, prepared under different conditions, had different degrees of water solubility, and discussed the relations between $\left\langle\mathrm{f}_{k}\right\rangle$ by NMR method and the water solubility for CA: CA having $\left\langle\mathrm{f}_{2}\right\rangle \simeq\left\langle\left\langle\mathrm{f}_{3}\right\rangle \simeq\left\langle\left\langle\mathrm{f}_{6}\right\rangle\right.\right.$ (i.e., CA with uniformly distributed acetyl groups) dissolves almost completely in water at room temperature in the range of $\langle F\rangle$ from 0.6 to 1.0 . In contrast to this, CA having $\left.\left.\left\langle\mathrm{f}_{6}\right\rangle\right\rangle\left\langle\left\langle\mathrm{f}_{2}\right\rangle\right\rangle+\left\langle\mathrm{f}_{3}\right\rangle\right\rangle$ (i.e., CA with acetyl groups highly selectively located at $\mathrm{C}_{6}$ position) is little better than insoluble in water over the entire $\langle F\rangle$ range. In addition, Kamide et $a l .{ }^{5}$ demonstrated that CA having $\left\langle\mathrm{f}_{2}\right\rangle \simeq\left\langle\left\langle\mathrm{f}_{3}\right\rangle \simeq\left\langle\left\langle\mathrm{f}_{6}\right\rangle\right.\right.$ easily dissolves completely in dimethylacetamide (DMAC) at room temperature irrespective of $\langle\mathrm{F}\rangle$, if $\langle\mathrm{F}\rangle$ is at least larger than 0.6, and $\mathrm{CA}$ having $\left.\left\langle\mathrm{f}_{6}\right\rangle\right\rangle\left\langle\left\langle\mathrm{f}_{2}\right\rangle+\left\langle\mathrm{f}_{3}\right\rangle\right.$ dissolves only partly in DMAC even at $80^{\circ} \mathrm{C}$ in the same $\langle\mathrm{F}\rangle$ range. Now, we conclude that neither $\langle F\rangle,\left\langle\mathrm{f}_{2}\right\rangle,\left\langle\left\langle\mathrm{f}_{3}\right\rangle\right.$ nor $\left\langle\mathrm{f}_{6}\right\rangle$ control individually the solubility. Kamide et al..$^{5}$ obtained experimental evidence suggesting that the relative content of 3-monosubstituted glucopyranose units controls water solubility, but this needs fur-

Table I. Degree of substitution, weight- and viscosity-average molecular weight and peak chemical shift in carbonyl region of CAs

\begin{tabular}{cccccl}
\hline $\begin{array}{c}\text { Sample } \\
\text { code }\end{array}$ & $\langle\mathrm{F}\rangle$ & $\begin{array}{c}\bar{M}_{w}, \\
\left(\bar{M}_{v}\right) / 10^{5}\end{array}$ & & Chemical shift/ppm $( \pm 0.02 \mathrm{ppm})$ & \\
\hline Ca-0 & 2.92 & $2.32^{\mathrm{a}}$ & 169.94 & $169.40(169.17) 169.11$ & 168.93168 .78 \\
CA-1 & 2.46 & $1.05^{\mathrm{a}}$ & 170.02169 .95169 .82 & 169.41169 .11 & 168.91168 .78168 .73 \\
CA-2 & 1.75 & $0.82^{\mathrm{b}}$ & 170.04169 .97169 .83 & 169.43169 .17169 .14169 .11 & 168.93168 .80 \\
CA-3 & 1.23 & $0.80^{\mathrm{b}}$ & $170.06170 .00169 .97(169.85)$ & $(169.61) 169.45169 .21169 .16$ & $168.92168 .79(168.72)$ \\
CA-4 & 1.06 & $0.64^{\mathrm{b}}$ & 170.04169 .96169 .87 & 169.58169 .46169 .34169 .22169 .10 & 168.92168 .77 \\
CA-5 & 0.95 & $0.47^{\mathrm{b}}$ & 170.00168 .87 & 169.61169 .48169 .36169 .22 & 168.93168 .87 \\
CA-6 & 0.77 & $0.36^{\mathrm{b}}$ & $170.04(168.88)$ & 169.59169 .47169 .36169 .18 & 168.93168 .75 \\
CA-7 & 0.69 & $0.33^{\mathrm{b}}$ & $170.04169 .98(168.89)$ & 169.61169 .46169 .34 & $168.93(168.71)$ \\
CA-8 & 0.54 & - & $170.02169 .97(169.90)$ & $169.59(169.43) 169.34169 .09$ & 168.92168 .79 \\
CA-9 & 0.43 & - & $170.04(169.99) 169.90169 .78$ & $169.61169 .34(169.10)$ & 168.94 \\
\hline
\end{tabular}

a $\bar{M}_{w}$, from light scattering.

b $\bar{M}_{v}$, from $[\eta]$ in DMAC at $25^{\circ} \mathrm{C}$. 
ther experimental study.

This article assigns all peaks in the carbonyl carbon region of ${ }^{13} \mathrm{C}$ NMR spectra of CA and provides a firm basis for estimating $\left\langle\mathrm{f}_{k}\right\rangle$ and molar fractions of 8 kinds of glucopyranose units of CA by NMR alone.

\section{EXPERIMENTAL}

A cellulose triacetate (CTA) whole polymer with $\langle\mathrm{F}\rangle=2.92$ (sample code CA-0) and 9 incompletely substituted CA samples, prepared by acid hydrolysis of sample CA-0 in acetic acid (sample code CA-1-CA-9) were used. The detailed preparing procedures are described in previous papers. ${ }^{14,15}$

Table I collects the weight-average molecular weight $\bar{M}_{w}$ of sample code CA-0 and 1, determined by light scattering in DMAC, and the viscosity-average molecular weight $\bar{M}_{v}$ of sample code CA-2 -7, determined from the limiting viscosity number in DMAC solution. ${ }^{14-16}$

Proton noise-decoupled ${ }^{13} \mathrm{C}$ NMR $\left({ }^{13} \mathrm{C}\left\{{ }^{1} \mathrm{H}\right\}\right.$ NMR) spectra of these CA solutions in deuterated dimethylsulfoxide (DMSO- $d_{6}$ ) were recorded on a FX-200 FT-NMR spectrometer (JEOL, Japan) at a resonance frequency of $50.18 \mathrm{MHz}$ at $90^{\circ} \mathrm{C}$. The detailed operating conditions were almost the same as those in the previous paper. $^{12}$ Tetramethylsilane (TMS) was the internal reference. Integrated peak intensity was determined from an integral curve. $\langle\mathrm{F}\rangle$ was evaluated from the integrated intensity ratio of peaks in acetyl methyl carbon region $(20-22 \mathrm{ppm})$ and peaks in $\mathrm{C}_{1}$ carbon region $(91-105 \mathrm{ppm})$.

The second column of Table I compiles the 《F $\rangle$ of these CA samples.

\section{RESULTS AND DISCUSSION}

Figure 4(a)-(j) show the carbonyl carbon region of ${ }^{13} \mathrm{C}\left\{{ }^{1} \mathrm{H}\right\}$ NMR spectra of samples CA- -9 in DMSO- $d_{6}$. These spectra were recorded at a spectral width of $1 \mathrm{kHz}(4096$ data points) in order to attain high degital resolution. The chemical shift from TMS as an internal reference was determined from the spectra obtained independently at a spectral width of $10 \mathrm{kHz}$ (8192 data points). The degital resolution of these spectra was estimated to be about $0.01 \mathrm{ppm}$ and the relative error of chemical shifts was less than $0.02 \mathrm{ppm}$. In the spectrum of sample code $\mathrm{CA}-0(\langle\mathrm{~F}\rangle=$ 2.92) in Figure 4(a), three main peaks were observed as reported in the previous paper, ${ }^{12}$ originating from trisubstituted glucopyranose
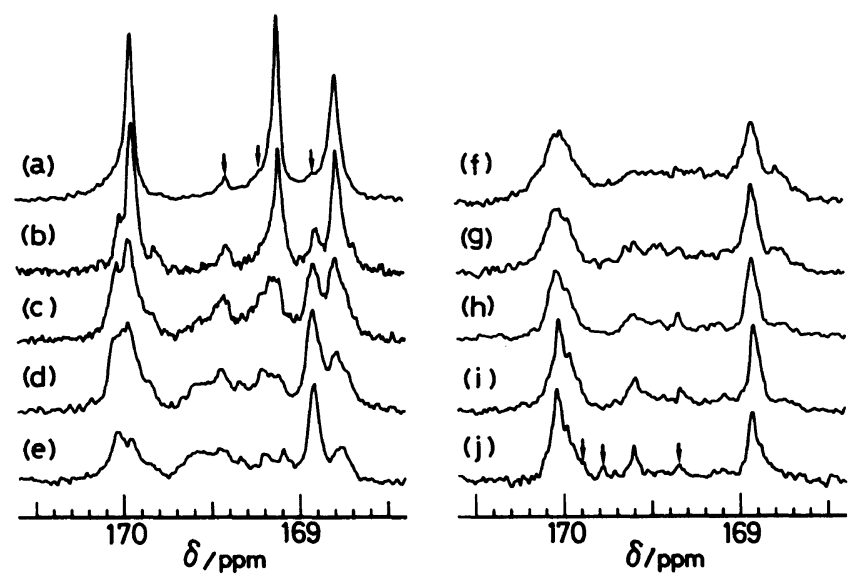

Figure 4. Carbonyl carbon region of ${ }^{13} \mathrm{C}\left\{{ }^{1} \mathrm{H}\right\}$ NMR spectra of cellulose acetates: (a), CA-0; (b), CA-1; (c), CA-2; (d), CA-3; (e), CA-4; (f), CA-5; (g), CA-6; (h), CA-7; (i), CA-8; (j), CA-9. 
unit, and these peaks are assigned, from lower magnetic field, to three carbonyl carbons at $\mathrm{C}_{6}, \mathrm{C}_{3}$, and $\mathrm{C}_{2}$ positions, respectively. In the same spectrum, small peaks or shoulders, observed at 169.4, 169.2, and $168.9 \mathrm{ppm}$ (as denoted by arrows in the figure) may possibly have originated from disubstituted glucopyranose units. In the spectrum of sample CA$9(\langle F\rangle=0.43)$ in Figure $4(j)$, three peaks $(170.0,169.6$, and $168.9 \mathrm{ppm})$ due to three monosubstituted glucopyranose units are observed and in addition, a group of small peaks (as denoted by arrows in the figure), considered to have originated from disubstituted glucopyranose units, are detected at 169.9, 169.8, and 169.3 ppm. ${ }^{13} \mathrm{C}\left\{{ }^{1} \mathrm{H}\right\}$ NMR spectra for $\mathrm{CA}$ samples having intermediate $\langle\mathrm{F}\rangle$ $(1.75-0.77)$ show very complicated patterns, possibly due to superposition of the above mentioned peak groups and of peaks from disubstituted units.

In and after the fourth column of Table I are summerized the chemical shifts of all peaks (in $0.01 \mathrm{ppm}$ unit) in carbonyl carbon region of ${ }^{13} \mathrm{C}\left\{{ }^{1} \mathrm{H}\right\}$ NMR spectrum of each CA sample. In the table, chemical shifts of shoulders are shown in parentheses. The table indicates that for each CA sample 6-11 peaks or shoulders

Table II. Peak assignments in the carbonyl carbon region of CAs

\begin{tabular}{|c|c|c|c|c|}
\hline $\begin{array}{l}\text { Peak } \\
\text { No. }\end{array}$ & $\delta / \mathrm{ppm}$ & $\begin{array}{l}\text { Carbon } \\
\text { position }\end{array}$ & \multicolumn{2}{|c|}{$\begin{array}{c}\text { Glucopyranose } \\
\text { unit }\end{array}$} \\
\hline 1 & 170.04 & 6 & 6-Mono- & \\
\hline 2 & 170.00 & 6 & 2,6-Di- & \\
\hline 3 & 169.94 & 6 & 2,3,6-Tri- & \\
\hline 4 & 169.89 & 6 & 3,6-Di- & \\
\hline 5 & 169.83 & 6 & $3,6-\mathrm{Di}-$ & \\
\hline 6 & 169.60 & 3 & 3-Mono- & \\
\hline 7 & 169.46 & 3 & 3,6-Di- & \\
\hline 8 & 169.41 & 3 & 3,6-Di- & \\
\hline 9 & 169.35 & 3 & 3,6-Di- & \\
\hline 10 & 169.22 & 3 & 2,3-Di- & \\
\hline 11 & 169.11 & $3(2)$ & 2,3,6-Tri- & (2,6-Di-) \\
\hline 12 & 168.93 & 2 & 2-Mono- & 2,6-Di- \\
\hline 13 & 168.79 & 2 & 2,3,6-Tri- & 2,3-Di- \\
\hline 14 & 168.71 & 2 & 2,3-Di- & \\
\hline
\end{tabular}

in total are observed in the carbonyl carbon region. Considering the relative error $( \pm 0.02$ ppm) of chemical shifts, the peaks observed commonly for two or more CA samples are carefully chosen as listed in Table II. Here, the peaks are numbered from the lower magnetic field. As previously described, the total number of carbonyl carbon peaks, expected previously and theoretically as due to substituted, is 12 , but from actual experiments, 14 peaks are observed (Table II).

Peaks No. 3, 11, and 13 are the main peaks in the spectrum of highly substituted CA $(\langle F\rangle=2.92)$ as shown in Figure $4(a)$ of the 2,3,6-trisubstituted glucopyranose unit and are assigned to the carbonyl carbons at $\mathrm{C}_{6}, \mathrm{C}_{3}$, and $\mathrm{C}_{2}$ carbon positions in the 2,3,6-trisubstituted unit, respectively. This mutual positional order in the tri-substituted unit can be postulated to be maintained in low substituted CA $(\langle F\rangle=0.43)$; thus, the main peaks in Figure $4(\mathrm{j})$ No. 1, 6, and 12 can be assigned to the carbonyl carbons in 6-, 3-, and 2-monosubstituterd glucopyranose units, respectively. The assignment for these 6 peaks are collected in columns 3 and 4 (in part) of Table II.

Generally, the degree of change in chemical shift due to the introduction of a specific substitution group into polymer is the maximun at the nucleus, to which the substituent group is directly combined (i.e., $\alpha$-position) and is smaller at the nucleus which is combined indirectly with and separated through a large number of nuclei from the substituent group. For example, the chemical shift of the carbonyl carbon at $\mathrm{C}_{3}$ position is significantly influenced by whether the $\mathrm{C}_{2}$ position is substituted or not, but is not so much affected by the $\mathrm{C}_{6}$ position. Thus, it is reasonably expected that the chemical shifts of $\mathrm{C}_{3}$ carbonyl carbons of 3-mono- and 3,6disubstituted glucopyranose units are relatively close and $\mathrm{C}_{3}$ carbonyl carbons of 2,3di- and 2,3,6-trisubstituted units give similar chemical shifts. According to this expectation, we can assign the No. 10 peak in the vicinity of 
peak No. 11 to the $\mathrm{C}_{3}$ carbonyl carbon in the 2,3-disubstituted glucopyranose unit and peaks No. 7, 8, and 9 in vicinity of peak No. 6 to $\mathrm{C}_{3}$ carbonyl carbons in the 3,6-disubstituted glucopyranose unit, respectively. Accordingly, peak No. 14 near peak No. 13 is assigned to the $C_{2}$ peak in the 2,3-disubstituted glucopyranose unit. Since no peak exists near the position of peak No. 12, which is assigned already to the $\mathrm{C}_{2}$ carbonyl carbon in the 2monosubstituted unit, then the $\mathrm{C}_{2}$ carbonyl carbon in the 2,6-disubstituted unit is considered to be heavily superposed with that of the 2-monosubstituted unit. In a similar manner, peaks No. 4 and 5, observed in the vicinity of peak No. 3 , is assigned to the $\mathrm{C}_{6}$ carbonyl carbon in the 3,6-disubstituted unit and peak No. 2 in the vicinity of peak No. 3 to the $C_{6}$ carbonyl carbon in the 2,6-disubstituted unit. The above assignments are also shown in columns 3, 4, and 5 (in part) of Table II.

Table III collects the integrated peak intensities of carbonyl carbon peaks No. $1-14$, $I_{n}$ ( $n$ is the peak No. and $n=1-14$ ), for samples CA- $0,1,2,3,8$, and 9 . Here, $I_{n}$ is normalized with total integrated intensity $\left(\sum_{n=1}^{14} I_{n}(\equiv\langle\bar{F}\rangle)\right)$. Several peaks overlap each other, and some $I_{n}$ cannot be estimated separately. The overlapping peaks are shown with underlined and their total peak intensities are shown under the main peak $\left(I_{n}\right)$ in the table. Inspection of Tables II and III leads us to the conclusion that in $\mathrm{CA}$ with $\langle\mathrm{F}\rangle\rangle>2.4$ (CA-0 and CA-1) a large amount of the 2,3,6trisubstituted (from peak No. 3, 11, and 13) unit coexists with a small amount of 2,6- and 3,6-disubstituted (from peak No. 5, 8, and 12) glucopyranose units, and CAs with $\langle\mathrm{F}\rangle\langle 0.6$ (CA-8 and CA-9) are mainly constituted by 2-, 3-, and 6-monosubstituted glucopyranose (from peak No. 1, 6, and 12) units with a small amount of 3,6-disubstituted glucopyranose unit (from peak No. 9). Then, we can conclude that the highly substituted CA consists mainly of trisubstituted and disubstituted glucopyranose units and low substituted CA consists predominantly of monosubstituted units. Note that in this study, all not-fully substituted CA samples were prepared by acid hydrolysis, which is expected to occur randomly (or homogeneously), and the above conclusion is consistent with what is expected in the case of random acid hydrolysis of CA. Kamide et al. ${ }^{6}$ pointed out from TLC analysis on CTA that "CTA" with $\langle\mathrm{F}\rangle$ of 2.92 is a mixture of CTA with $\langle\mathrm{F}\rangle=3$ (i.e., trisubstituted unit) and notfully substituted CA. This finding was repeatedly and more firmly ascertained in this NMR study. Although peak No. $11\left(\mathrm{C}_{3}\right.$ carbonyl carbon in trisubstituted glucopyranose units) was observed for CA sampled CA-8 and CA-9 (low substituted CA's), the corresponding $\mathrm{C}_{6}, \mathrm{C}_{2}$ carbonyl carbons for the trisubstituted one (peak No. 3 and 13, respectively) were not found. Then, in this case peak No. 11

Table III. Integrated peak intensity $I_{n}$ of carbonyl carbon peaks of CA samples

\begin{tabular}{|c|c|c|c|c|c|c|c|c|c|c|c|c|c|c|c|}
\hline \multirow{2}{*}{$\begin{array}{l}\text { Sample } \\
\text { code }\end{array}$} & \multirow{2}{*}{$\langle\mathrm{F}\rangle$} & \multicolumn{14}{|c|}{$I_{n}$} \\
\hline & & $n=1$ & 2 & 3 & 4 & 5 & 6 & 7 & 8 & 9 & 10 & 11 & 12 & 13 & 14 \\
\hline CA- 0 & 2.92 & & & 0.97 & & 0.02 & 0.00 & & 0.06 & 0.00 & & 0.95 & 0.01 & 0.91 & 0.00 \\
\hline CA-1 & 2.46 & & & 0.77 & & 0.09 & 0.00 & & 0.16 & 0.00 & & 0.66 & 0.21 & 0.57 & \\
\hline CA-2 & 1.75 & & & 0.56 & & & 0.00 & 0.23 & & 0.00 & 0.40 & & 0.23 & 0.33 & 0.00 \\
\hline CA-3 & 1.23 & & 0.40 & & & & 0.00 & 0.20 & & 0.03 & 0.17 & & 0.24 & 0.18 & \\
\hline CA-8 & 0.54 & 0.22 & & & 0.00 & 0.00 & 0.08 & 0.03 & & 0.04 & & 0.02 & 0.13 & 0.02 & \\
\hline CA-9 & 0.43 & 0.18 & & & 0.00 & 0.00 & 0.08 & 0.00 & & 0.05 & 0.00 & 0.01 & 0.11 & 0.00 & 0.00 \\
\hline
\end{tabular}


should be assigned to the $\mathrm{C}_{2}$ carbonyl carbon of the 2,6-disubstituted glucopyranose unit. On the other hand, the same carbonyl carbon (i.e., the $\mathrm{C}_{2}$ carbonyl carbon at the 2,6-disubstituted unit) peak is observed as peak No. 12 for highly substituted CA samples (CA- 0 and CA-1), indicating that change in $\langle F\rangle$ from $2.5-2.9$ to $\sim 0.5$ brings about a shift of the chemical shift of the $\mathrm{C}_{2}$ carbonyl carbon peak in the 2,6-disubstituted unit by $\sim 0.14( \pm 0.04)$ ppm. Similar variation in the chemical shift with $\langle\langle F\rangle$ was noticed on other peaks. One or two peaks, observed over the range of $169.34-169.48 \mathrm{ppm}$, are considered due to the $\mathrm{C}_{3}$ carbonyl carbon of the 3,6-disubstituted unit. Its location varies depending on $\langle\mathrm{F}\rangle$. We already assigned peak No. 14 to the $\mathrm{C}_{2}$ carbonyl carbon of the 2,3-disubstituted unit, but the low substituted CA No. 13 peak, in place of No. 14 peak, should be assigned to the above carbonyl carbon. A tentative explanation of these phenomena would be a possible long-range (accordingly, weak) effect from the substituent group in the nearest neighbouring glucopyranose unit on the carbonyl carbon in question. That is, the peak position of the chemical shift of the $\mathrm{C}_{2}$ carbonyl carbon in the 2,6-disubstituted unit may change depending on whether the substituent

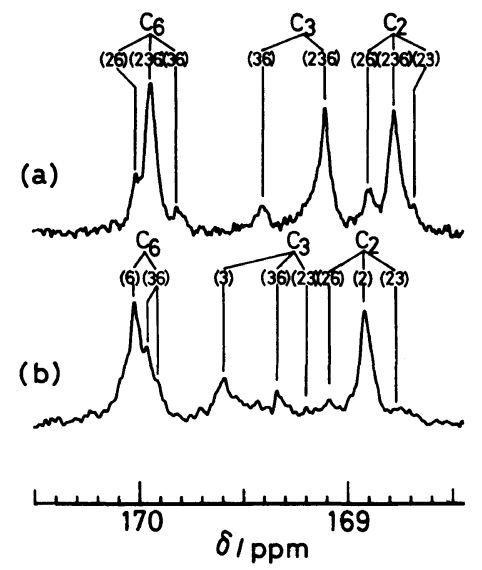

Figure 5. Peak assignments of the carbonyl carbon peaks of cellulose acetates: (a), CA-1; (b), CA-8. group is existing or not probably at the $\mathrm{C}_{3}$ position, which is the nearest the $\beta$-glucoside linkage, in the neighbouring glucopyranose unit. This long-range effect will become remarkable for the disubstituted units, existing in a wide range of $\langle F\rangle$. Then, peaks due to either $\mathrm{C}_{3}$ or $\mathrm{C}_{2}$ carbonyl carbon are expected to be located at the position of peak No. 11 . Additional assignments of peaks No. 11 and 13, determined from integrated peak intensity, are also shown in Table II. Figure 5(a) and (b) demonstrate carbonyl carbon region of ${ }^{13} \mathrm{C}\left\{{ }^{1} \mathrm{H}\right\}$ NMR sepctra of samples CA-1 and CA-8 with full assignment.

Using the assignment for all the peaks in carbonyl carbon region as given in Table II we can derive equations to give $\left\langle\left\langle\mathrm{f}_{k}\right\rangle\right.$ :

$$
\begin{aligned}
& \left\langle\mathrm{f}_{2}\right\rangle=\langle\mathrm{F}\rangle\left(\sum_{j=12}^{14} I_{j}\right) /\left(\sum_{j=1}^{14} I_{j}\right) \\
& \text { (for } \mathrm{CA} \text { with }\langle\mathrm{F}\rangle \geqq 2 \text { ) } \\
& \left\langle\left\langle\mathrm{f}_{2}\right\rangle=\langle\mathrm{F}\rangle\left(\sum_{j=11}^{14} I_{j}\right) /\left(\sum_{j=1}^{14} I_{j}\right)\right. \\
& \text { (for } \mathrm{CA} \text { with }\langle\mathrm{F}\rangle<2 \text { ) } \\
& \left\langle\mathrm{f}_{3}\right\rangle=\left\langle\langle\mathrm{F}\rangle\left(\sum_{j=6}^{11} I_{j}\right) /\left(\sum_{j=1}^{14} I_{j}\right)\right. \\
& \text { (for } \mathrm{CA} \text { with }\langle\mathrm{F}\rangle \geqq 2 \text { ) } \\
& \left\langle\mathrm{f}_{3}\right\rangle=\langle\mathrm{F}\rangle\left(\sum_{j=6}^{10} I_{j}\right) /\left(\sum_{j=1}^{14} I_{j}\right) \\
& \text { (for } \mathrm{CA} \text { with }\langle\mathrm{F}\rangle\langle 2 \text { ) } \\
& \left\langle\mathrm{f}_{6}\right\rangle=\langle\mathrm{F}\rangle\left(\sum_{j=1}^{5} I_{j}\right) /\left(\sum_{j=1}^{14} I_{j}\right)
\end{aligned}
$$

Table IV collects $\left\langle\mathrm{f}_{k}\right\rangle$ of all CA samples calculated using eq $1-5$ from the data in Table III. Evidently, it is confirmed for CA with $\langle F\rangle \geqq 0.7$, that $\left\langle\left\langle f_{2}\right\rangle \simeq\left\langle\left\langle f_{3}\right\rangle \simeq\left\langle\left\langle f_{6}\right\rangle\right.\right.\right.$. In the previous paper, ${ }^{5}$ Kamide et al. reported for CA synthesized by a two-step method a similar tendency $\left(\left\langle\mathrm{f}_{2}\right\rangle \simeq \simeq\left\langle\mathrm{f}_{3}\right\rangle \simeq\left\langle\left\langle\mathrm{f}_{6}\right\rangle\right)\right.$, although in their study, determination of $\left\langle\left\langle\mathrm{f}_{k}\right\rangle\right.$ was made by rough approximation. The relations between $\left\langle\mathrm{f}_{k}\right\rangle$ of $\mathrm{CA}$ and its physical properties 
will be described elsewhere. ${ }^{17}$ In addition, from $I_{n}(n=1-14)$ data, for any CA sample we can evaluate the distribution of seven different substituted glucopyranose units as shown in Figure 3. We denote molar fractions of eight (seven substituted and single unsubstituted) glucopyranose units with $\left\langle\mathrm{f}_{l m n}\right\rangle$, where $l, m$, and $n$ mean the existence of the acetyl group at the $\mathrm{C}_{2}, \mathrm{C}_{3}$, and $\mathrm{C}_{6}$ positions, respectively, and they can take the value of 0 (unsubstituted) or 1 (substituted). According to this notation, the doubly-averaged molar fraction of the trisubstituted unit is $\left\langle\left\langle\mathrm{f}_{111}\right\rangle\right\rangle$ and those of disubstituted units are $\left\langle\mathrm{f}_{110}\right\rangle,\left\langle\mathrm{f}_{101}\right\rangle$, and $\left\langle\mathrm{f}_{011}\right\rangle$ and that of unsubstituted unit is $\left\langle\mathrm{f}_{000}\right\rangle$ and so on (see Figure 3 ). The summation of all $\left\langle\mathrm{f}_{l m n}\right\rangle$ is unity:

Table IV. Total degree of substitution $\langle\mathbf{F}\rangle$ and distribution of degree of substitution $\left\langle\mathrm{f}_{k}\right\rangle$ of CA samples

\begin{tabular}{ccccc}
\hline Sample code & $\langle\mathrm{F}\rangle$ & $\left\langle\mathrm{f}_{2}\right\rangle$ & $\left\langle\mathrm{f}_{3}\right\rangle$ & $\left\langle\mathrm{f}_{6}\right\rangle$ \\
\hline CA-0 & 2.92 & 0.92 & 1.01 & 0.99 \\
CA-1 & 2.46 & 0.79 & 0.82 & 0.85 \\
CA-2 & 1.75 & 0.56 & 0.63 & 0.56 \\
CA-3 & 1.23 & 0.42 & 0.40 & 0.40 \\
CA-4 & 1.06 & 0.33 & 0.42 & 0.31 \\
CA-5 & 0.95 & 0.29 & 0.33 & 0.33 \\
CA-6 & 0.77 & 0.26 & 0.24 & 0.27 \\
CA-7 & 0.69 & 0.20 & 0.23 & 0.26 \\
CA-8 & 0.54 & 0.17 & 0.15 & 0.22 \\
CA-9 & 0.43 & 0.12 & 0.13 & 0.18 \\
\hline
\end{tabular}

$$
\sum_{l=0}^{1} \sum_{m=0}^{1} \sum_{n=0}^{1}\left\langle\mathrm{f}_{l m n}\right\rangle=1
$$

According to this definition, $\left\langle\mathrm{f}_{k}\right\rangle$ and $\langle\mathrm{F}\rangle$ can be expressed in terms of $\left\langle\mathrm{f}_{l m n}\right\rangle$ as follows:

$$
\begin{aligned}
& \left.\left\langle\mathrm{f}_{2}\right\rangle=\sum_{m=0}^{1} \sum_{n=0}^{1}\left\langle\mathrm{f}_{1 m n}\right\rangle\right\rangle \\
& \left\langle\mathrm{f}_{3}\right\rangle=\sum_{l=0}^{1} \sum_{n=0}^{1}\left\langle\mathrm{f}_{l 1 n}\right\rangle \\
& \left\langle\mathrm{f}_{6}\right\rangle=\sum_{l=0}^{1} \sum_{m=0}^{1}\left\langle\mathrm{f}_{l m 1}\right\rangle \\
& \langle\mathrm{F}\rangle=\left\langle\left\langle\mathrm{f}_{2}\right\rangle+\left\langle\mathrm{f}_{3}\right\rangle+\left\langle\mathrm{f}_{6}\right\rangle\right.
\end{aligned}
$$

Based on the assignment of all carbonyl carbon peaks in Table II and neglecting peak overlapping, we can calculate $\left\langle\mathrm{f}_{l m n}\right\rangle$ from $I_{n}$ through the following equations:

$\left\langle\mathrm{f}_{111}\right\rangle=I_{3}=I_{13}+I_{14}-\left\langle\mathrm{f}_{110}\right\rangle$

$\left\langle\mathrm{f}_{111}\right\rangle=I_{11}=I_{13} \quad$ (for $\mathrm{CA}$ with $\left.\langle\mathrm{F}\rangle \geqq 2\right)(12)$

$\left\langle\mathrm{f}_{111}\right\rangle=I_{11}-\left\langle\mathrm{f}_{101}\right\rangle \quad$ (for $\mathrm{CA}$ with $\langle\mathrm{F}\rangle\langle 2$ )

$\left\langle\mathrm{f}_{110}\right\rangle=I_{10}=I_{13}+I_{14}-\left\langle\mathrm{f}_{111}\right\rangle$

$\left\langle\mathrm{f}_{101}\right\rangle=I_{2}=I_{11} 2+I_{12}-\left\langle\mathrm{f}_{111}\right\rangle-\left\langle\mathrm{f}_{100}\right\rangle$

$\left\langle\mathrm{f}_{101}\right\rangle=I_{12} \quad($ for $\mathrm{CA}$ with $\langle\mathrm{F}\rangle \geqq 2)$

$\left\langle\mathrm{f}_{101}\right\rangle=I_{11} \quad$ (for $\mathrm{CA}$ with $\left.《 \mathrm{~F}\right\rangle\langle 2)$

\begin{tabular}{|c|c|c|c|c|c|c|c|c|}
\hline Sample code & $\left\langle\mathrm{f}_{111}\right\rangle$ & $\left\langle f_{110}\right\rangle$ & $\left\langle\left\langle f_{101}\right\rangle\right.$ & $\left\langle\mathrm{f}_{011}\right\rangle$ & $\left\langle f_{100}\right\rangle$ & $\left\langle\mathrm{f}_{010}\right\rangle$ & $\left\langle\mathrm{f}_{001} 》\right.$ & $\left\langle\mathrm{f}_{000}\right\rangle$ \\
\hline CA-1 & 0.48 & 0.18 & 0.21 & 0.16 & $0^{\mathrm{a}}$ & $0^{\mathbf{a}}$ & $0^{\mathbf{a}}$ & $0^{\mathrm{a}}$ \\
\hline CA-8 & $0^{\mathrm{a}}$ & 0.02 & 0.02 & 0.07 & 0.13 & 0.08 & 0.13 & 0.45 \\
\hline CA-9 & $0^{\mathrm{a}}$ & 0.00 & 0.01 & 0.05 & 0.11 & 0.08 & 0.12 & 0.63 \\
\hline Sample code & $\left\langle\left\langle f_{2}\right\rangle_{\text {calc }}\right.$ & $\left\langle\left\langle f_{3}\right\rangle_{\text {calc }}\right.$ & $\left\langle\left\langle\mathrm{f}_{6}\right\rangle_{\text {calc }}\right.$ & $\left\langle\langle F\rangle_{\text {calc }}\right.$ & $\left\langle\mathrm{f}_{2}\right\rangle_{\text {con }}$ & $\left\langle\left\langle\mathrm{f}_{3}\right\rangle_{\text {con }}\right.$ & $\left\langle\mathrm{f}_{6}\right\rangle_{\text {con }}$ & $\langle\bar{F}\rangle_{\text {con }}$ \\
\hline CA-1 & 0.87 & 0.82 & 0.85 & 2.54 & 0.79 & 0.82 & 0.85 & 2.46 \\
\hline CA-8 & 0.17 & 0.17 & 0.22 & 0.56 & 0.17 & 0.15 & 0.22 & 0.54 \\
\hline CA-9 & 0.12 & 0.13 & 0.18 & 0.43 & 0.12 & 0.13 & 0.18 & 0.43 \\
\hline
\end{tabular}

$\left\langle\mathrm{f}_{011}\right\rangle=I_{4}+I_{5}=I_{7}+I_{8}+I_{9}$

Table V. $\left\langle\left\langle\mathrm{f}_{l m n}\right\rangle,\left\langle\mathrm{f}_{k}\right\rangle_{c a l c},\langle\mathrm{~F}\rangle_{\text {calc }},\left\langle\mathrm{f}_{k}\right\rangle_{\text {con }}\right.$, and $\langle\mathrm{F}\rangle_{\text {con }}$ values of CA samples

a Approximated previously. 


$$
\begin{aligned}
& \left.\left\langle\mathrm{f}_{100}\right\rangle=I_{12} \quad \text { (for CA with }\langle\mathrm{F}\rangle<2\right) \\
& \left\langle\mathrm{f}_{010}\right\rangle=I_{6} \\
& \left\langle\mathrm{f}_{001}\right\rangle=I_{1}
\end{aligned}
$$

The peaks in ${ }^{13} \mathrm{C}\left\{{ }^{1} \mathrm{H}\right\}$ NMR spectra of $\mathrm{CA}$ samples, except for CA-0, are quite broad indeed and overlap significantly as shown in Figure 4. Then, an accurate evaluation of $\left\langle\mathrm{f}_{l m n}\right\rangle$ for CA is quite difficult.

Since for the sample code CA-8 peaks No. 6,11 , and 12 are separetely observed without overlapping with other peaks, $\left\langle\mathrm{f}_{010}\right\rangle,\left\langle\mathrm{f}_{100}\right\rangle$, and $\left\langle\left\langle\mathrm{f}_{101}\right\rangle\right\rangle$ for the sample can be evaluated using the $I_{n}$ data of these peaks (Table III) from eq 20,19 , and 17 , respectively. The fraction $\left\langle\mathrm{f}_{110}\right\rangle$ for the sample can also be determined from eq 14 using data on $I_{13}+I_{14}$ in Table III and assuming $\left\langle\mathrm{f}_{111}\right\rangle=0$, because (1) peaks No. 13 and 14 overlap with each other, but not with other peaks, enabling an estimate of $I_{13}+I_{14}$ and (2) $\left.《 \mathrm{~F}\right\rangle$ for this sample is low (0.54). $\left\langle\mathrm{f}_{011}\right\rangle$ for the sample can also be evaluated using data on $I_{7}+I_{8}+I_{9}$ from eq 18 , in the same manner. In addition, for this CA cample, peak No. 1 significantly overlaps with peaks No. 2, 3, 4, and 5 then, $\left\langle\left\langle\mathrm{f}_{001}\right\rangle\right\rangle$ cannot be simply estimated from eq 21 using $I_{1}$ data. An alternative way of estimating $\left\langle\mathrm{f}_{001}\right\rangle$ is given by the equation:

$$
\left\langle\mathrm{f}_{001}\right\rangle=\sum_{j=1}^{5} I_{j}-\left\langle\mathrm{f}_{101}\right\rangle-\left\langle\left\langle\mathrm{f}_{011}\right\rangle-\left\langle\mathrm{f}_{111}\right\rangle\right.
$$

Combination of eq 5 and 10 leads to eq 22 . Neglecting $\left\langle\mathrm{f}_{111}\right\rangle$ in eq 22 for sample CA-8, $\left\langle\mathrm{f}_{001}\right\rangle$ can be estimated roughly from $\left\langle\mathrm{f}_{101}\right\rangle$ and $\left\langle\mathrm{f}_{011}\right\rangle$ data previously determined by eq 16 and 18.

Equation 6 can be rearranged as follows:

$$
\begin{aligned}
\left\langle\left\langle\mathrm{f}_{000}\right\rangle=\right. & 1-\left(\left\langle\mathrm{f}_{111}\right\rangle+\left\langle\left\langle\mathrm{f}_{110}\right\rangle+\left\langle\left\langle\mathrm{f}_{101}\right\rangle\right\rangle\right.\right. \\
& \left.+\left\langle\mathrm{f}_{011}\right\rangle\right\rangle+\left\langle\left\langle\mathrm{f}_{100}\right\rangle+\left\langle\left\langle\mathrm{f}_{010}\right\rangle+\left\langle\left\langle\mathrm{f}_{001}\right\rangle\right)\right.\right.
\end{aligned}
$$

Then, eq 23 enables us to estimate $\left\langle\mathrm{f}_{000}\right\rangle$ from already known $\left\langle\mathrm{f}_{l m n}\right\rangle$ data.

The values of $\left\langle\mathrm{f}_{l m n}\right\rangle$ for sample CA-8 thus determined are listed in Table $\mathrm{V}$, where the corresponding data for samples CA-1 and CA9 , both obtained in a similar manner are also included. Here, for sample CA-1, it is assumed that the molar fractions of mono- and unsubstituted glucopyranose units are neglected $\left(\left\langle f_{100}\right\rangle=\left\langle\left\langle f_{010}\right\rangle=\left\langle\left\langle f_{001}\right\rangle=\left\langle\left\langle f_{000}\right\rangle=0\right)\right.\right.\right.$.

From $\left\langle\mathrm{f}_{l m n}\right\rangle$ data shown in Table $\mathrm{V},\left\langle\mathrm{f}_{k}\right\rangle$ and $\langle F\rangle$ can be directly evaluated using eq 7-9 and eq 10. The results are also summarized in 10th -14 th columns in Table $\mathrm{V}$. Here, $\left\langle f_{k}\right\rangle$ and $\langle F\rangle$ thus obtained are denoted by $\left\langle\mathrm{f}_{k}\right\rangle_{\text {calc }}$ and $\langle\mathrm{F}\rangle_{\text {calc }}$, respectively. $\left\langle\mathrm{f}_{k}\right\rangle$ and $\langle\mathrm{F}\rangle$ estimated previously by the conventional method for these samples through application of eq $1-5$ and eq 10 , are denoted as $\left\langle\mathrm{f}_{k}\right\rangle_{\text {con }}$ and $\langle\mathrm{F}\rangle_{\text {con }}$, and are also compiled in the 15th-18th columns in Table V. $\left\langle\left\langle\mathrm{f}_{k}\right\rangle_{\mathrm{calc}} \simeq\left\langle\left\langle\mathrm{f}_{k}\right\rangle_{\mathrm{con}}(k=2,3\right.\right.$, and 6$)$ and $\langle\mathrm{F}\rangle_{\text {calc }} \simeq\left\langle\langle\mathrm{F}\rangle_{\text {con }}\right.$ thus appear to be confirmed.

Summarizing, all peaks observed in the carbonyl carbon regionin ${ }^{13} \mathrm{C}$ NMR spectra of fully- and not-fully-substituted CA were unambigously assigned and a method proposed for evaluating the molar fractions of 8 kinds of glucopyranose units such as 2,3,6-tri-, 2,3di-, 2,6-di-, 3,6-di-, 2-mono-, 3-mono-, and 6monosubstituted units and an unsubstituted unit (denoted here as $\left.\left\langle\mathrm{f}_{l m n}\right\rangle\right)$, based on these assignment. It was confirmed for three CA samples that $\left\langle\mathrm{f}_{k}\right\rangle$ and $\langle\mathrm{F}\rangle$, calculated from $\left\langle\mathrm{f}_{l m n}\right\rangle$, coincide approximately with those by conventional methods, supporting the reliability of the present method of assignment.

\section{REFERENCES}

1. K. Kamide, K. Okajima, T. Matsui, M. Ohnishi, and H. Kobayashi, Polym. J., 15, 309 (1983).

2. K. Kamide, K. Okajima, K. Kowsaka, T. Matsui, S. Nomura, and K. Hikichi, Polym. J., 17, 909 (1985).

3. K. Kamide, K. Okajima, and K. Kowsaka, Polym. J., 19, 231 (1987).

4. K. Kamide, K. Okajima, T. Matsui, and M. Ohnishi, Polym. J., 19, 347 (1987). 


\section{K. KowsaKa, K. OKajima, and K. Kamide}

5. K. Kamide, K. Okajima, K. Kowsaka, and T. Matsui, Polym. J., 19, 1405 (1987).

6. K. Kamide, T. Matsui, K. Okajima, and S. Manabe, Cellulose Chem. Technol., 16, 601 (1982).

7. For example, T. Noguchi, J. Soc. Text. Cell. Ind., Jpn. (Sen-i Gakkaishi), 6, 153, 155, 217, 270, 312, 314, 379, 381, 444 (1950); K. Lauer, Makromol. Chem., 5, 287 (1951).

8. T-K Wu, Macromolecules, 13, 74 (1980).

9. D. T. Clark, P. J. Stephenson, and F. Heatley, Polymer, 22, 1112 (1981).

10. K. Kamide and K. Okajima, Polym. J., 13, 127 (1981).

11. T. Miyamoto, Y. Sato, T. Shibata, H. Inagaki, and
M. Tanahashi, J. Polym. Sci., Polym. Chem. Ed., 22, 2363 (1984).

12. K. Kowsaka, K. Okajima, and K. Kamide, Polym. J., 18, 843 (1986).

13. T. Miyamoto, Y. Sato, T. Shibata, M. Tanahashi, and H. Inagaki, J. Polym. Sci., Polym. Chem. Ed., 23, 1373 (1985).

14. K. Kamide, T. Terakawa, and Y. Miyazaki, Polym. J., 11, 285 (1979).

15. K. Kamide, Y. Miyazaki, and T. Abe, Polym. J., 11, 523 (1979).

16. K. Kamide, M. Saito, and T. Abe, Polym. J., 13, 421 (1981).

17. K. Kowsaka, to be published. 